Rev Chil Salud Pública 2012;

Vol 16 (1): $75-76$

Semblanza

\section{Alfonso Gómez-Lobo}

\section{Un diálogo inconcluso}

\author{
AN INCONCLUSIVE DIALOGUE
}

Conocí a Alfonso Gómez-Lobo cuando ambos participábamos en una mesa redonda donde se debatía, en lo esencial, sobre el estatus ontológico y moral del embrión humano. Sostuvimos visiones muy encontradas al respecto; desde su vasta erudición, el Prof. Gómez-Lobo presentaba argumentos sutiles y coherentes en apoyo de la existencia del ser humano y su potencial personalidad a partir del momento de la concepción, el embrión siendo en todo momento depositario de los derechos humanos y el respeto moral que todo individuo merece. Su gentileza y la ecuanimidad con que recibía mi posición secular, de no asignar al cigoto ni a las etapas de inicios del desarrollo embrionario la equivalencia moral con el ser humano viable o vivo, era admirable. Esta amable erudición lo llevó a recibir numerosas distinciones en forma de becas, premios y la honrosa designación a ocupar desde 1996 la Cátedra Ryan de Metafísica y Filosofía Moral en la Universidad.de Georgetown.

Nos encontramos casualmente en la calle algunos días después, y lamenté no poder acceder a su amistosa y cordial invitación a compartir un café, pues me reclamaba una cita más urgente con el dentista. Intercambiamos direcciones y anticipamos juntarnos en un próximo viaje de Alfonso a Chile. No pudo ser, pero su imagen de un intelecto exquisitamente cultivado y un

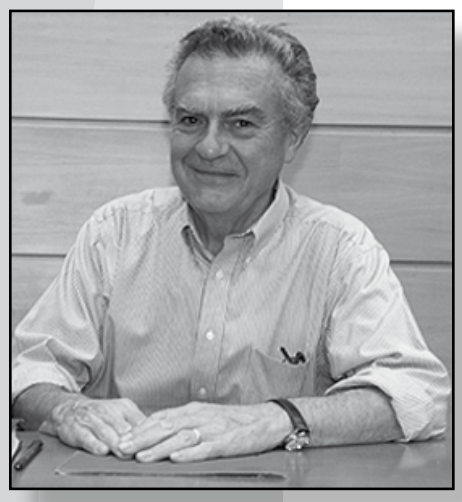
interlocutor cautivante al mismo tiempo que respetuoso auditor de perspectivas ajenas a las suyas, me impulsó a explorar sus escritos y mantener vivo un diálogo imaginario con él.

Asentado en la Universidad de Georgetown, Washington D.C. Alfonso enseña, investiga y publica, cultivando su erudición filosófica y filológica, entregando traducciones y ediciones bilingües (griego-inglés) de escritos platónicos, trabajos todos que merecieron entusiastas elogios de sus pares académicos. Su dominio oral y escrito de 8 lenguas es asombroso, como lo es la vastedad de sus intereses, que lo impulsan a traducir desde el Parménides de Platón hasta obras de Gottlob Frege.

En 1994 publica "The foundations of socratic ethics, traducción de un texto que escribiera en Chile (1986) y publicara en México (1989), y que también aparece en francés (1996). Interesante es que "La ética de Sócrates" (Ed. Andrés Bello, 1998) no es el texto original, sino una traducción de la versión inglesa.

Alfonso no lo dice expresamente, pero su texto tiene intenciones académicas antes que pedagógicas, pero la claridad de su estilo, la precisión de conceptos y definiciones, y la cortesía de traducir y aclarar matices semánticos del griego clásico, permiten una lectura fluida y provechosa para quienes acometen aventuras intelectuales con equipamiento de aficionados. El pensamiento de Sócrates, sobre todo de las horas previas a su muerte, sólo es conocido por los diálogos de Platón, que Gómez-Lobo escudriña rigurosamente, sorteando obstáculos mediante recurso a un fino análisis de la polisemia griega, y al no siempre fácil rescate de aparentes contradicciones que el exégeta, con apoyo 
bibliográfico exhaustivo, busca explicar como recursos retóricos de ironía, el uso de paradojas (posible de revisión a diferencia de las contradicciones).

Lo de Sócrates es una ética procedimental y el asentamiento de un par de principios generales. En cuanto al procedimiento, es grato comprobar que Gómez - Lobo no utiliza la caracterización platónica del método socrático como "mayéutico", que erróneamente supone que la materia a enseñar ya está, al menos in nuce, en la mente del educando. Pero Sócrates no es un partero de ideas, y Alfonso lo recalca repetidamente, pues cultiva una retórica de "refutación" (élenjos); no busca verdades ocultas en la mente de su interlocutor sino, al contrario, devela incoherencias y contradicciones de su pensamiento. I. Lakatos diría que Sócrates aplica la falsación débil, al estilo popperiano, que refuta supuestas verdades pero no ofrece otras más sólidas, como sería de desear en una falsación fuerte. Pero Sócrates dice no sabe, sino que nada sabe, conformándose con mostrar que los demás tampoco saben, sólo que no son conscientes de su ignorancia.

No siendo esta una semblanza de Sócrates, sino de Alfonso Gómez Lobo, baste decir, en un resumen, que violenta la riqueza de su obra, que Alfonso nos guía por 18 principios que emanan del discurso socrático, de los cuales dos son los fundamentales:

"(P 1) Una elección es racional si, y sólo si, elige lo que es mejor para el agente," y (P 13) Algo es bueno para el agente si, y sólo sí, es moralmente recto."

"Morality and The Human Goods. An Introduction to Natural Law Ethics" es un libro que Alfonso Gómez-Lobo publica en la Georgetown University Press (2002) y que, levemente modificado y elegantemente traducido por Alejandra Carrasco, aparece como "Los bienes humanos. Ética de la ley natural” (Ed. Mediterráneo, 2006). En este texto, Alfonso posterga el rigor académico para dar preferencia a la presentación de una obra escrita "para aquellas personas que, en medio de la confusión actual y sin ser especialistas en filosofía, sientan la necesidad de darle a su propio pensamiento una estructura conceptual bien fundada." Es un esfuerzo por presentar en forma clara, con un lenguaje cotidiano que recurre explicar racionalmente los fundamentos del obrar ético. Expresamente renuncia a incluir "la existencia de Dios y, por ende, la bondad de la religión" en una "discusión sobre filosofía moral." No obstante, su compromiso doctrinal queda a la vista al legitimar el principio del doble efecto, el énfasis en la intención y la conciencia del agente para evaluar moralmente sus actos, la fidelidad a la ley natural según explicada por Santo Tomás, a la inclusión de "verdades teológicas, y su reconocimiento, al final del texto, que su libro "consistente con las normas de las principales corrientes de ética judeocristiana y, en particular, con las enseñanzas de la Iglesia Católica".

Es característico del pensamiento de Alfonso Gómez-Lobo que, habiendo sido académico fiel y comprometido con las universidades de inspiración doctrinaria (Universidad de Georgetown, USA y Pontifica Universidad Católica de Chile), a que pertenecía, así como haber sido miembro de la Pontificia Academia para la vida, haya llegado honrosamente a puerto con dos audacias encomiables: su propuesta de fundamentar la ética con estricta argumentación racional y, en segundo término, confiar en la ley natural, tan vapuleada por el racionalismo moderno, para fundamentar preceptos éticos y bioéticos señalados como naturales al tratarlos como universalmente válidos.

Hay una notable continuidad entre el erudito conocimiento de la filosofía antigua y el filósofo moral, cosa que el mismo Gómez-Lobo reconoce cuando subtitula la primera parte de la Introducción de "Los Bienes humanos" como "Un paradigma del pensamiento ético: el Critón de Platón." Michael Frede termina el prefacio del libro sobre Sócrates, señalando que se hará un "buen uso" del libro "si se lo utiliza como una guía acerca de los pensamientos que conviene tener y el modo correcto de tenerlos", que es precisamente lo que Alfonso se propone y obsequia al lector de su texto sobre la Ética de la ley natural. 